\title{
Adsorption of hydrogen on clean and modified magnesium films
}

\author{
Johansson, Martin; Ostenfeld, Christopher Worsøe; Chorkendorff, Ib
}

Published in:

Physical Review B Condensed Matter

Link to article, DOI:

10.1103/PhysRevB.74.193408

Publication date:

2006

Document Version

Publisher's PDF, also known as Version of record

Link back to DTU Orbit

Citation (APA):

Johansson, M., Ostenfeld, C. W., \& Chorkendorff, I. (2006). Adsorption of hydrogen on clean and modified magnesium films. Physical Review B Condensed Matter, 74(19), 193408.

https://doi.org/10.1103/PhysRevB.74.193408

\section{General rights}

Copyright and moral rights for the publications made accessible in the public portal are retained by the authors and/or other copyright owners and it is a condition of accessing publications that users recognise and abide by the legal requirements associated with these rights.

- Users may download and print one copy of any publication from the public portal for the purpose of private study or research.

- You may not further distribute the material or use it for any profit-making activity or commercial gain

- You may freely distribute the URL identifying the publication in the public portal

If you believe that this document breaches copyright please contact us providing details, and we will remove access to the work immediately and investigate your claim. 


\title{
Adsorption of hydrogen on clean and modified magnesium films
}

\author{
Martin Johansson, Christopher W. Ostenfeld, and Ib Chorkendorff* \\ Danish National Research Foundation's Center for Individual Nanoparticle Functionality (CINF) and Nano DTU, \\ Department of Physics, Technical University of Denmark, DK-2800 Kgs. Lyngby, Denmark
}

(Received 7 August 2006; published 14 November 2006)

\begin{abstract}
The sticking of hydrogen on $400 \AA$ thick magnesium films, grown under ultrahigh vacuum conditions, have been measured under conditions relevant for hydrogen storage, i.e., elevated temperatures and pressures. A model which describes the hydrogenation and desorption kinetics of the pure magnesium films at $\mathrm{H} / \mathrm{Mg}$ ratios less than $2 \%$ is developed. The activation barrier for hydrogen dissociation is $72 \pm 15 \mathrm{~kJ} / \mathrm{mole}_{2}$, and a stagnant hydrogen uptake is observed. For platinum-catalyzed films, the barrier is significantly reduced, and there is no stagnation in the uptake rate.
\end{abstract}

DOI: 10.1103/PhysRevB.74.193408

PACS number(s): 68.43.-h, 82.20.Pm

The interaction of hydrogen with metals has always attracted much attention due to its fundamental relevance for a number of industrially important processes. Furthermore, hydrogen is the simplest molecule and has therefore been used as a model system for understanding the basic principles of solid-gas interaction. Most of the work concerns dissociative adsorption of hydrogen on transition metals and has been motivated by its relevance for catalysis. The contributions are both theoretical ${ }^{1-7}$ and experimental ${ }^{8-11}$ and references therein. Recently, materials for hydrogen storage have obtained renewed interest and the initial sticking of hydrogen on nontransition metals is of particular interest. ${ }^{12}$ One of the systems, namely magnesium, has obtained special attention, being a model system for hydrogen storage applications. ${ }^{13}$ However, the vast majority of the investigations are studies of ball-milled powders which prevents detailed surfacesensitive characterization.

The only available ultrahigh vacuum (UHV) study on pure magnesium was performed by Sprunger and Plummer, ${ }^{14}$ who detailed the interaction of atomic hydrogen with a $\operatorname{Mg}(0001)$ single crystal. However, the sticking probability for molecular hydrogen is too low to be studied under UHV conditions, and thermal desorption experiments could not be performed, since that would lead to sublimation of the crystal. Due to these difficulties, accurate quantification of the hydrogen uptake was not possible. Krozer and Kasemo, ${ }^{15}$ on the other hand, used a palladium overlayer as a dissociation catalyst in their study of the hydrogen uptake of magnesium films under well-controlled conditions. Here, the hydrogen content was measured by monitoring the mass change of the film, rather than by thermal desorption.

Dissociative adsorption is a crucial step for hydrogen uptake in $\mathrm{Mg}$. In the experiments presented here, we study hydrogenation of magnesium thin films with the help of a combined UHV/high pressure setup. The dissociative sticking of hydrogen on the magnesium films, both with and without a dissociation catalyst, is studied using the high pressure cell, while desorption of hydrogen and magnesium is studied in the UHV chamber. By combining these measurements with modeling, the energy diagram for the interaction of hydrogen with magnesium can be extracted.

The ultrahigh vacuum chamber has a base pressure below $1 \times 10^{-10}$ mbar and is equipped for ion scattering spectros- copy, (ISS), x-ray photoelectron spectroscopy (XPS), and thermally programmed desorption (TPD). ${ }^{16}$ It also contains a high pressure cell, which allows for hydrogen exposures at pressures up to 4 bar, while preserving the vacuum in the analysis chamber. The substrate used was a Mo(111) single crystal, which was cleaned by cycles of sputtering, followed by annealing at $1073 \mathrm{~K}$. The temperature of the crystal was measured with a chromel-alumel (type K) thermocouple, (thread diameter $0.125 \mathrm{~mm}$ ), which was spot welded to the edge of the crystal. Magnesium films were evaporated onto the $\mathrm{Mo}(111)$ at rates between 0.1 and $0.4 \AA / s$, as monitored by a commercial quartz crystal microbalance (QCM). Evaporation was performed at a sample temperature of $423 \mathrm{~K}$. In this way, thermal annealing effects during the adsorption experiment could be completely eliminated. At temperatures above $423 \mathrm{~K}, \mathrm{Mg}$ starts to evaporate from the film. Platinum overlayers were evaporated with the sample at room temperature. The evaporation source was a $99.99 \% \mathrm{Pt}$ wire, wrapped tightly around a $0.25 \mathrm{~mm} \mathrm{~W}$ wire, yielding evaporation rates around $0.1 \AA / \mathrm{min}$.

In order to avoid contamination of the $\mathrm{Mg}$ surface, the hydrogen gas (N57, purity 99,9997\%) was cleaned by a reduced $\mathrm{Cu}$ catalyst and a molecular sieve. In addition, the high pressure cell was baked in a flow of hydrogen for 15-24 hours, prior to performing experiments. The hydrogen uptake experiments were carried out by admitting hydrogen to the high pressure cell to the desired pressure and then heating the sample to the desired temperature. After high pressure experiments, the Mg films were checked for impurities, such as oxygen, with XPS. The hydrogen uptake was obtained from thermal desorption experiments. The area under the TPD curve for the 2 AMU signal was calibrated with the area obtained from the $\mathrm{Mo}(111)$ surface saturated with hydrogen. ${ }^{16}$ Hydrogen coverages are reported with respect to the $\operatorname{Mg}(0001)$ surface, which has an atomic density of 1.94 $\times 10^{19} \mathrm{~m}^{-2}$.

Figure 1 shows the results of uptake experiments on $400 \AA \mathrm{Mg}$ films at a hydrogen pressure of 4 bar. It is clear that there is a decrease in the uptake rate with time. The longest exposure time used at $433 \mathrm{~K}$ is 5 minutes, since subsequent thermal desorption measurements indicated that significant evaporation of $\mathrm{Mg}$ occurred for longer exposure times. Typical desorption curves for $\mathrm{Mg}$ and $\mathrm{H}_{2}$ are shown in 


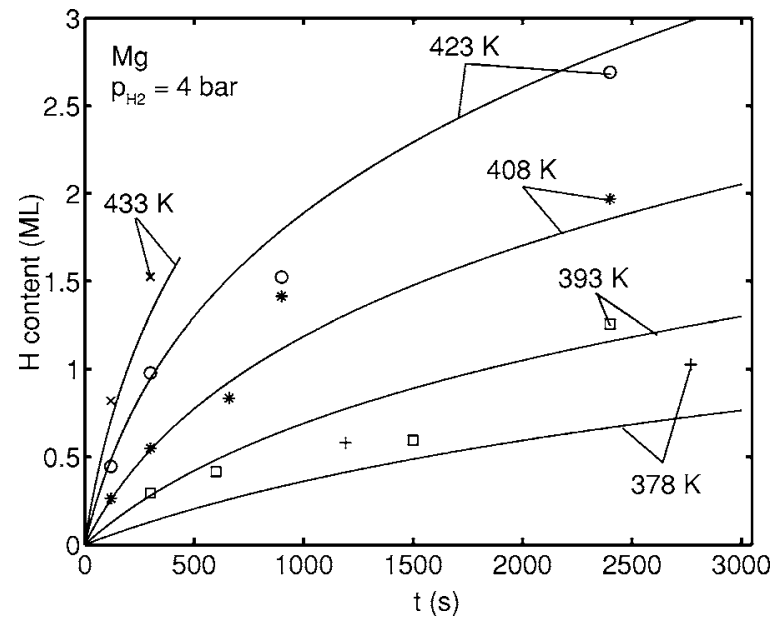

FIG. 1. Hydrogen uptake for $400 \AA \mathrm{Mg}$ films with a hydrogen pressure of 4 bar. The curves are calculated from the model with the parameters shown in Fig. 4.

Fig. 2. The desorption of $\mathrm{Mg}$ from the $\mathrm{Mo}(111)$ substrate has been shown to be independent of the $\mathrm{H}$ content in the concentration range investigated here. ${ }^{16}$ No evidence of desorption of molecular hydride, $\mathrm{MgH}_{2}$, was found.

In order to investigate the influence of the surface processes on the uptake rate, $0.5 \AA \mathrm{Pt}$, as determined by the QCM, was deposited on top of $400 \AA \mathrm{Mg}$ films as a hydrogen dissociation catalyst. The Pt overlayer was characterized with ISS and XPS at room temperature. ISS, which probes the outermost atomic layer, did not show any Pt, while XPS showed the presence of $\mathrm{Pt}$ within the probing depth of the Pt $4 f$ line. This strongly suggests alloying or segregation of $\mathrm{Mg}$, even at room temperature. The actual surface coverage of $\mathrm{Pt}$ is thus below the detection limit for ISS. Figure 3 shows the results of adsorption experiments on $\mathrm{Pt} / \mathrm{Mg}$ films at a hydrogen pressure of 1 bar. Two distinct differences are

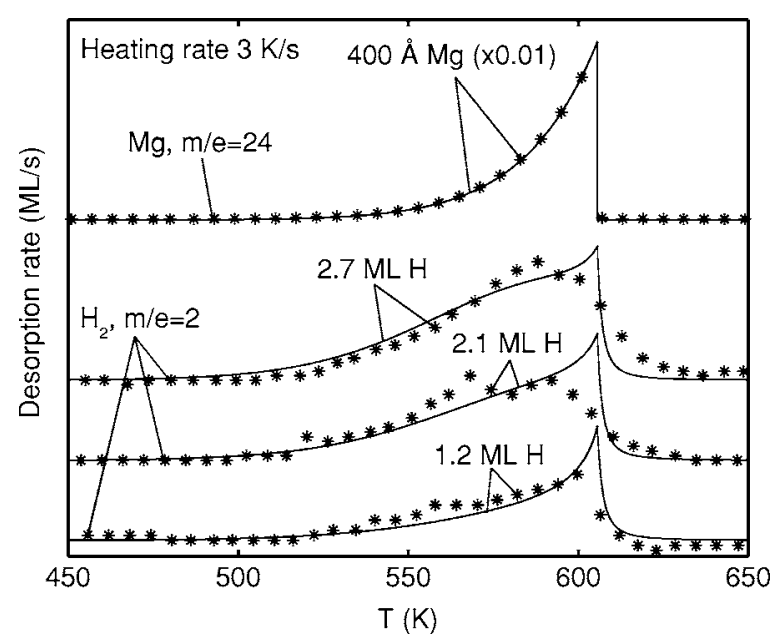

FIG. 2. Hydrogen and Mg desorption curves for $400 \AA \mathrm{Mg}$ films loaded with various amounts of $\mathrm{H}$. The heating rate was $3 \mathrm{~K} / \mathrm{s}$. The small peaks at 520 and $570 \mathrm{~K}$ in the curve for $2.1 \mathrm{ML}$ are random fluctuations. The solid curves are calculated from the model with the parameters shown in Fig. 4.

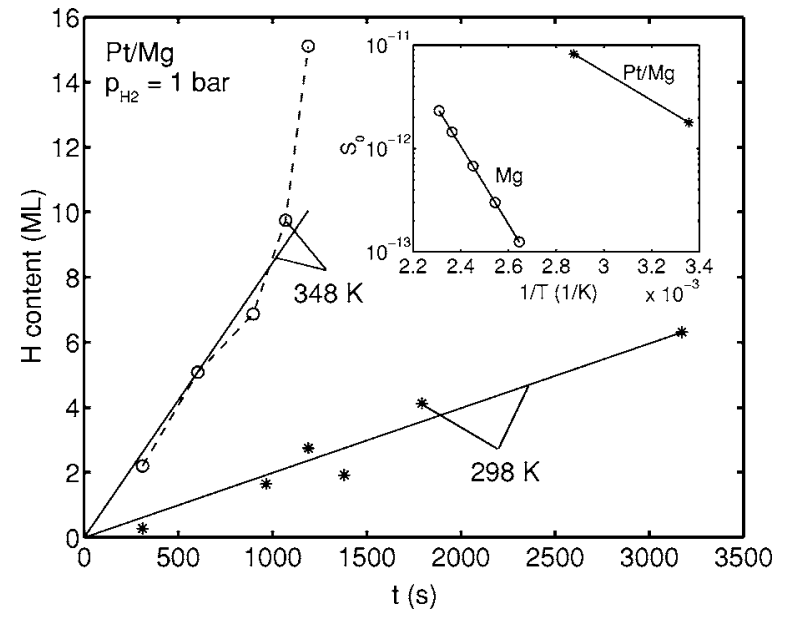

FIG. 3. Hydrogen uptake for $400 \AA \mathrm{Mg}$ films activated with $0.5 \AA$ Pt. The hydrogen pressure is 1 bar. The lines are linear fits to uptake data and the inset shows the resulting initial sticking coefficients, $S_{0}$. The inset also shows $S_{0}$ for pure $\mathrm{Mg}$ calculated from Eq. (2).

obvious, compared to Fig. 1. First, the amount of hydrogen sorbed is much higher, despite the lower temperature and pressure used, and second, at least at the lower temperature, the uptake rate is constant. The initial sticking probabilities (sticking coefficients), $S_{0}$, were determined from a linear fit to the data points, as shown in Fig. 3. An Arrhenius plot based on the two data points available give a barrier of $26 \mathrm{~kJ} / \mathrm{mole} \mathrm{H}_{2}$, and a prefactor of $7.3 \times 10^{-8}$. The value obtained for the barrier is close to experimental and theoretical values for the bulk diffusion barrier in the $\alpha$ phase, 24 and $18 \mathrm{~kJ} /$ mole $\mathrm{H}$, respectively. ${ }^{17,18}$ Hence, it is possible that bulk diffusion, rather than dissociation of $\mathrm{H}_{2}$, is the rate determining step for the uptake on $\mathrm{Pt} / \mathrm{Mg}$. The small prefactor is probably an effect of the low Pt coverage.

A simple model was developed in order to understand the hydrogen uptake and the TPD experiments on pure Mg films on $\mathrm{Mo}(111)$. The model describes the $\mathrm{H}$ coverage on the surface and in the bulk. Since Mg desorbs simultaneously with $\mathrm{H}_{2}$, the model also includes the number of Mg layers. Desorption of $\mathrm{H}_{2}$ and $\mathrm{Mg}$ is assumed to occur independently from the surface. Since addition of $\mathrm{Pt}$ to the $\mathrm{Mg}$ surface increases the uptake rate, bulk diffusion is assumed to be fast compared to the processes on the surface. In the model, the $\mathrm{H}$ concentration in the bulk is thus assumed to be homogeneous. Since modification of the surface with Pt eliminates the saturation in the uptake curves, it is likely that the saturation is due to blocking of the surface by adsorbed $\mathrm{H}$. Such a situation will arise if the adsorption state of $\mathrm{H}$ on the surface is lower in energy than the absorption state in the $\mathrm{Mg}$ bulk, as is predicted by calculations. ${ }^{17,19}$ The formation of a surface hydride has also been observed experimentally. ${ }^{14}$

The coverage of hydrogen on the surface of the $\mathrm{Mg}$ film is denoted by $\theta_{s}$, the concentration of hydrogen in a bulk layer of the film by $\theta_{b}$ and the number of monolayers of $\mathrm{Mg}$ by $n_{l}$. The time derivatives of $\theta_{s}, \theta_{b}$, and $n_{l}$ are given by the equations 


$$
\begin{gathered}
\frac{d \theta_{s}}{d t}=\frac{2 S_{0}\left(1-\theta_{s}\right)^{2} F_{\mathrm{H}_{2}}}{N_{s}}-2 k_{d} \theta_{s}^{2}+k_{b s} \frac{N_{b}}{N_{s}} \theta_{b}\left(1-\theta_{s}\right) \\
-k_{s b} \theta_{s}\left(1-\theta_{b}\right), \\
\frac{d \theta_{b}}{d t}=\frac{1}{n_{l}}\left(k_{s b} \frac{N_{s}}{N_{b}} \theta_{s}\left(1-\theta_{b}\right)-k_{b s} \theta_{b}\left(1-\theta_{s}\right)-\theta_{b} \frac{d n_{l}}{d t}\right), \\
\frac{d n_{l}}{d t}=\frac{-F_{\mathrm{Mg}}}{N_{s}},
\end{gathered}
$$

where $F_{\mathrm{H}_{2}}$ is the molecular flux of hydrogen. $N_{s}$ is the surface concentration of adsorption sites [one per surface $\mathrm{Mg}$ atom on $\operatorname{Mg}(0001)], N_{s}=1.94 \times 10^{19} \mathrm{~m}^{-2}$, and $N_{b}$ the number of absorption sites per bulk layer, $N_{b}=2 N_{s}$.

The sticking coefficient for $\mathrm{H}_{2}$ on $\mathrm{Mg}, S_{0}$, is given by

$$
S_{0}=S_{0}^{0} \exp \left(-\frac{E_{a}}{k T}\right),
$$

where $S_{0}^{0}$ is a constant, $E_{a}$ the activation energy for adsorption, $k$ the Boltzmann constant, and $T$ the absolute temperature.

The desorption of $\mathrm{Mg}$ is described by the third of Eq. (1), where $F_{\mathrm{Mg}}$ is the molecular flux of $\mathrm{Mg}$,

$$
F_{\mathrm{Mg}}=\left\{\begin{array}{l}
\frac{p_{\mathrm{Mg}, \mathrm{eq}}}{\sqrt{2 \pi m_{\mathrm{Mg}} k T}}, \quad n_{l}>2, \\
0, \quad n_{l} \leq 2 .
\end{array}\right.
$$

Here $m_{\mathrm{Mg}}$ is the atomic mass of $\mathrm{Mg}$ and $p_{\mathrm{Mg} \text {,eq }}$ is the equilibrium pressure of $\mathrm{Mg}(\mathrm{Pa})$, given by ${ }^{20}$

$$
\ln p_{\mathrm{Mg}, \mathrm{eq}}=5.006+8.489-7813 / T-0.8253 \ln T .
$$

The $\mathrm{Mg}$ flux is equal to zero for $n_{l} \leq 2$, since studies on thin $\mathrm{Mg}$ films on $\mathrm{Mo}(111)$ have shown that the last two monolayers of $\mathrm{Mg}$ only desorb at temperatures above $620 \mathrm{~K} .{ }^{16}$ The model is thus valid for $T<620 \mathrm{~K}$. The rate constants for desorption, $k_{d}$, surface bulk transport, $k_{s b}$, and bulk surface transport, $k_{b s}$, are given by the expressions

$$
\begin{gathered}
k_{d}=\frac{1}{2} \nu_{d} \exp \left(-\frac{E_{d}}{k T}\right), \\
k_{s b}=\nu_{s b} \exp \left(-\frac{E_{s b}}{k T}\right), \\
k_{b s}=\frac{N_{s}}{N_{b}} \nu_{b s} \exp \left(-\frac{E_{b s}}{k T}\right),
\end{gathered}
$$

where the activation energies for desorption, surface-bulk, and bulk-surface transport are denoted by $E_{d}, E_{s b}$, and $E_{b s}$, respectively. The corresponding prefactors, are denoted by $\nu_{d}, \nu_{s b}$, and $\nu_{b s}$ and are assumed to have the values calculated by a classical approximation for the low hydrogen concentration limit, $\nu_{d}=6 \times 10^{12}, \quad \nu_{s b}=3.5 \times 10^{12}$, and $\nu_{b s}=7.2$ $\times 10^{11} \mathrm{~s}^{-1} \cdot{ }^{17}$ It is assumed that the surface density of sites in the transition state for surface-bulk transport is equal to $N_{s}$.

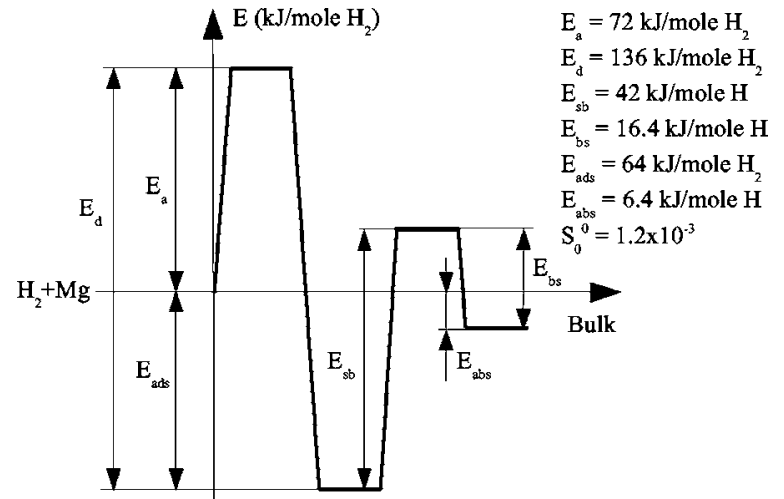

FIG. 4. A schematic energy diagram for the model.

The model is not sensitive to the value of $E_{b s}$ for realistic parameter values. A calculated value for $E_{b s}$ of $16.4 \mathrm{~kJ} / \mathrm{mole}$ $\mathrm{H}$ was used. ${ }^{17}$

An initial film thickness of $400 \AA$ corresponds to $n_{l}$ $=150 \mathrm{ML}$. The model gives an excellent description of the TPD curve for $\mathrm{Mg}$, as shown in Fig. 2.

The parameter values $S_{0}^{0}=1.2 \times 10^{-3}, E_{a}=72 \mathrm{~kJ} / \mathrm{mole} \mathrm{H}_{2}$ and $E_{s b}=42 \mathrm{~kJ} /$ mole $\mathrm{H}$ were obtained simultaneously by minimization of the deviation between calculated and measured hydrogen uptake. The desorption energy, $E_{d}$, was adapted to yield the correct temperature for the onset of hydrogen desorption. A value of $136 \mathrm{~kJ} /$ mole $\mathrm{H}_{2}$ was chosen. The shape of the hydrogen peaks can be expected to be influenced by changes in the heat of adsorption of hydrogen which occur for Mg film thicknesses below 15 ML. ${ }^{16}$ Such effects are not included in the model. The parameters resulting in the best fit between experiments and model are shown together with the resulting energy diagram in Fig. 4. Values for $S_{0}$ calculated from Eq. (2) are plotted in Fig. 3 for comparison with the values for $\mathrm{Pt} / \mathrm{Mg}$. The spread in the uptake data gives an uncertainty in $S_{0}$ of $40 \%$. If $S_{0}$ for $408 \mathrm{~K}$ is kept constant by adjusting $S_{0}^{0}$, the uncertainty in $E_{a}$ is about $15 \mathrm{~kJ} / \mathrm{mole} \mathrm{H}_{2}$. The errors in $E_{s b}$ and $E_{d}$ are estimated to be $2 \mathrm{~kJ} /$ mole $\mathrm{H}$ and $4 \mathrm{~kJ} /$ mole $\mathrm{H}_{2}$, respectively.

A sizeable discrepancy is found between the value obtained for $E_{a}, 72 \pm 15 \mathrm{~kJ} / \mathrm{mole} \mathrm{H}_{2}$, and the values of 110 and $100 \mathrm{~kJ} / \mathrm{mole} \mathrm{H}_{2}$ calculated by Vegge and Du et al., respectively. ${ }^{17,21}$ The difference can perhaps be explained by the presence of step sites which have a lower barrier for dissociation than terrace sites. Such effects have been observed for several diatomic dissociation reactions. ${ }^{4,22} \mathrm{We}$ have, in the current undertaking, not investigated the exact structure of the $\mathrm{Mg}$ overlayer. The value found for $E_{s b}$, of $42 \pm 2 \mathrm{~kJ} /$ mole $\mathrm{H}$, is in reasonable agreement with published theoretical values of $48 \mathrm{~kJ} /$ mole H. ${ }^{17,19}$

The energy diagram in Fig. 4 shows a heat of absorption for $\mathrm{H}$ in the bulk, $E_{\mathrm{abs}}$, of $6.4 \mathrm{~kJ} /$ mole $\mathrm{H}$. This value must be considered as an estimate. We believe that the experiments performed with the pure $\mathrm{Mg}$ films were made in the $\alpha$-phase concentration region, since the maximum $\mathrm{H} / \mathrm{Mg}$ ratio achieved in these experiments is approximately $2 \%$, and uptake experiments performed with $\mathrm{Pd}$ activated $\mathrm{Mg}$ films show that hydride formation starts at a $\mathrm{H} / \mathrm{Mg}$ ratio close to $2 \% .^{15}$ Also, XPS spectra for thin magnesium films on 
Mo(111), with $\mathrm{H}$ concentrations 10 times higher than what was achieved in this study reveal clear evidence of formation of the hydride $(\beta)$ phase. ${ }^{16}$ XPS spectra for the magnesium films used in this study with a $\mathrm{H} / \mathrm{Mg}$ ratio below $1 \%$ show no indication of magnesium hydride. A value for the heat of absorption for the $\alpha$ phase of $22 \mathrm{~kJ} /$ mole $\mathrm{H}$ has been reported. ${ }^{23}$ From experiments on $\mathrm{Pd}$ activated $\mathrm{Mg}$ films, Krozer et al. conclude that the heat of absorption is less than $12 \mathrm{~kJ} /$ mole H. ${ }^{15}$

To summarize, the initial sticking coefficient for molecular hydrogen on pure magnesium has been measured and is found to have a prefactor of approximately $1.2 \times 10^{-3}$ and an activation barrier for adsorption of $72 \pm 15 \mathrm{~kJ} / \mathrm{mole}_{2}$. From Eq. (2), this corresponds to an initial rate of $0.009 \mathrm{ML} \mathrm{H} / \mathrm{s}$ at $p_{\mathrm{H}_{2}}=4$ bar and $T=433 \mathrm{~K}$, demonstrating the extremely slow hydrogen dissociation rate on the $\mathrm{Mg}$ surface under conditions relevant for hydrogen storage. The stagnant uptake ob- served for the pure magnesium films containing less than $2 \%$ hydrogen is due to the formation of a surface hydride with a heat of adsorption, $E_{\text {ads }}$, of about $64 \mathrm{~kJ} /$ mole $\mathrm{H}_{2}$. The apparent activation barrier for adsorption on the Pt catalyzed films is significantly lower than on pure $\mathrm{Mg}$. No saturation in the uptake rate is observed for $\mathrm{Pt} / \mathrm{Mg}$. This can be explained if it is assumed that Pt acts as a bridge between the surface and the $\mathrm{Mg}$ bulk, so that the low energy Mg surface sites can be bypassed. Hence, the addition of small amounts of Pt to the $\mathrm{Mg}$ surface both increases the sticking coefficient and decreases the influence of self-blocking caused by the formation of surface hydride.

This project was supported by the Danish Research Council through "Towards a Hydrogen Based Society." Center for Individual Nanoparticle Functionality (CINF) is sponsored by The Danish National Research Foundation.
*Electronic address: ibchork@fysik.dtu.dk

${ }^{1}$ B. Hammer and J. Nørskov, Nature (London) 376, 238 (1995).

${ }^{2}$ B. Hammer and J. Nørskov, Surf. Sci. 343, 211 (1995).

${ }^{3}$ P. Kratzer, B. Hammer, and J. K. Nørskov, Surf. Sci. 359, 45 (1996).

${ }^{4}$ P. Kratzer, E. Pehlke, M. Scheffler, M. B. Raschke, and U. Höfer, Phys. Rev. Lett. 81, 5596 (1998).

${ }^{5}$ G. Kresse, Phys. Rev. B 62, 8295 (2000).

${ }^{6}$ B. Hammer and J. K. Nørskov, Adv. Catal. 45, 71 (2000).

${ }^{7}$ J. Greeley and M. Mavrikakis, Nat. Mater. 3, 810 (2004).

${ }^{8}$ C. Christmann, Surf. Sci. Rep. 9, 1 (1988).

${ }^{9}$ B. E. Hayden and C. L. A. Lamont, Phys. Rev. Lett. 63, 1823 (1989).

${ }^{10}$ A. C. Luntz, J. K. Brown, and M. D. Williams, J. Chem. Phys. 93, 5240 (1990).

${ }^{11}$ H. A. Michelsen, C. T. Rettner, D. J. Auerbach, and R. N. Zare, J. Chem. Phys. 98, 8294 (1993).

${ }^{12}$ L. Schlapbach and A. Züttel, Nature (London) 414, 353 (2001).

${ }^{13}$ M. Dornheim, N. Eigen, G. Barkhordarian, T. Klassen, and R. Bormann, Artif. Intell. Rev. 8, 377 (2006).
${ }^{14}$ P. T. Sprunger and E. W. Plummer, Chem. Phys. Lett. 187, 559 (1991).

${ }^{15}$ A. Krozer and B. Kasemo, J. Less-Common Met. 160, 323 (1990).

${ }^{16}$ C. W. Ostenfeld, J. C. Davies, T. Vegge, and I. Chorkendorff, Surf. Sci. 884, 17 (2005).

${ }^{17}$ T. Vegge, Phys. Rev. B 70, 035412 (2004).

${ }^{18}$ C. Nishimura, M. Komaki, and M. Amano, J. Alloys Compd. 293-295, 329 (1999).

${ }^{19}$ N. Jacobson, B. Tegner, E. Schröder, P. Hyldgaard, and B. I. Lundqvist, Comput. Mater. Sci. 24, 273 (2002).

${ }^{20} \mathrm{CRC}$ handbook of chemistry and physics on CD-ROM, version 2003 (CRC, Boca Raton, FL, 2003).

${ }^{21}$ A. J. Du, S. C. Smith, X. D. Yao, and G. Q. Lu, J. Phys. Chem. B 109, 18037 (2005).

${ }^{22}$ S. Dahl, A. Logadottir, R. C. Egeberg, J. H. Larsen, I. Chorkendorff, E. Törnqvist, and J. K. Nørskov, Phys. Rev. Lett. 83, 1814 (1999).

${ }^{23}$ K. Zeng, T. Klassen, W. Oelerich, and R. Bormann, Int. J. Hydrogen Energy 24, 989 (1999). 